\title{
Caso clínico radiológico
}

\author{
JUIO MAGGIOLO M. ${ }^{1}$, LILIAN RUBILAR O. ${ }^{1}$
}

1. Médico. Unidad Broncopulmonar. Hospital Exequiel González Cortés.

\section{Caso clínico}

Lactante femenino de 1 año 8 meses de edad, producto de primer embarazo de evolución normal, parto eutócico, peso de nacimiento: $3060 \mathrm{~g}$ y talla de nacimiento: $49 \mathrm{~cm}$. Sin antecedentes mórbidos personales ni familiares de importancia.

El cuadro actual comienza aproximadamente 2 horas antes de su hospitalización momento en que la madre sorprendío a la niña ingiriendo de un envase de gaseosa una cantidad no determinada de un diluyente de pintura, posteriormente presentó náuseas, vómitos en 3 oportunidades, uno de los cuales es inducido por la propia madre y un episodio de cianosis perioral. Consultó en el Servicio de Urgencia, donde se

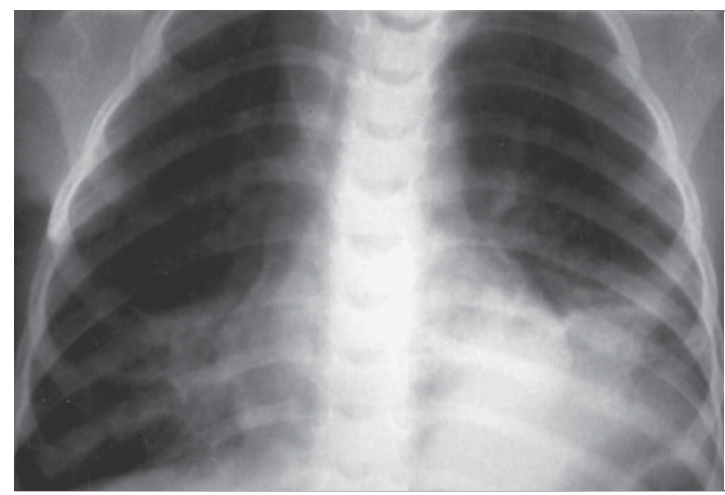

Figura 1a. apreciaba a una paciente con tos seca, frecuente y tormentosa, afebril, dificultad respiratoria moderada, retracción de partes blandas, polipnea, frecuencia respiratoria de $50 x^{\prime}$, frecuencia cardíaca de $145 x^{\prime}$, saturometría de oxígeno $\mathrm{O}_{2}$ de $90 \%$.

El examen pulmonar reveló abundantes estertores medios, sibilancias y crepitaciones bilaterales especialmente en ambas bases. Se inició oxígenoterapia mediante naricera a razón de 2 ltx' y salbutamol en inhalador de dosis medida (MDI) 2 puff cada 10 min por 5 veces, observándose reducción del apremio respiratorio y la saturometría sube a $95 \%$. Se solicitó una radiografía $(\mathrm{RX})$ de tórax en proyecciones antero-posterior y lateral (figura la y $1 b$ ) y fue hospitalizada en la UCI.

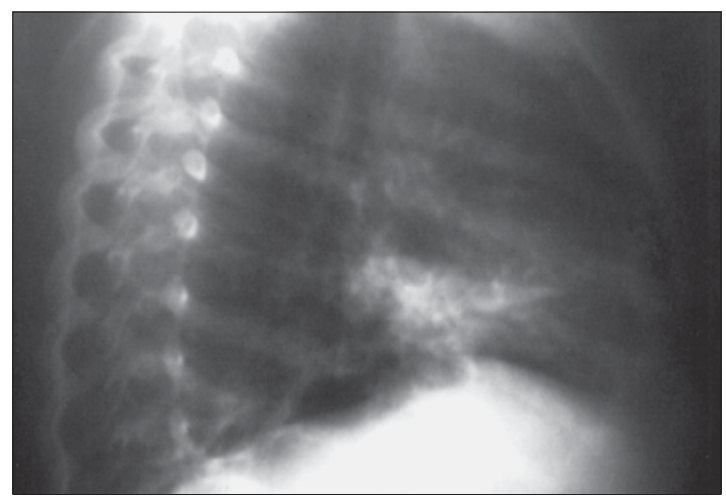

Figura $1 b$.

\section{¿Cuál es su diagnóstico?}

Trabajo recibido el 10 de marzo de 2008, devuelto para corregir el 09 de abril de 2008, segunda versión el 29 de abril de 2008, aceptado para publicación el 16 de abril de 2008 .

Correspondencia a:

Julio Maggiolo M.

E-mail: julio_vrs@latinmail.com 


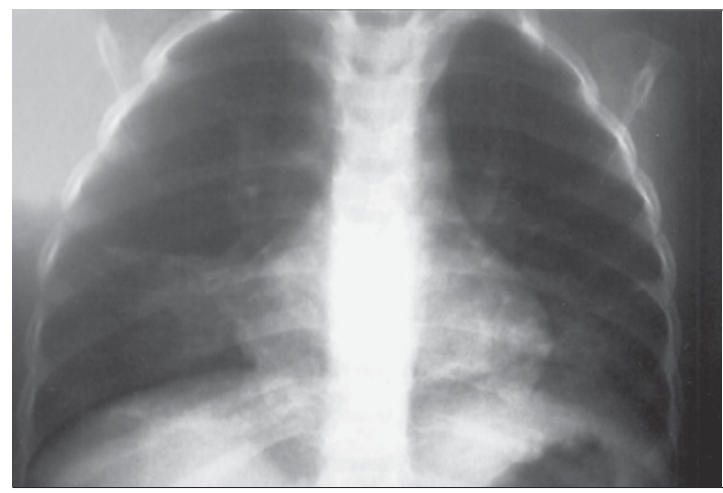

Figura 2.

\section{Hallazgos radiológicos}

En la figura 1 se aprecia condensación y atelectasias segmentarias y subsegmentarias en ambas bases pulmonares (la radiografia lateral no aporta mayor información en este caso).

La figura 2 revela disminución de la condensación y de las atelectasias.

La figura 3 muestra escasos infiltrados intersticiales residuales.

\section{Diagnóstico} carburo.

Neumonía bilateral por aspiración de hidro-

\section{Evolución clínica}

En la UCI evolucionó con dificultad respiratoria moderada, retracción de partes blandas, polipnea, requiriendo 2 ltx $^{\prime}$ de $\mathrm{O}_{2}$ y varios esquemas abreviados de salbutamol MDI. Durante el segundo día de hospitalización se agregó fiebre por lo que se decidió iniciar tratamiento con cefotaxima y clindamicina, la fiebre cedió el segundo día de antibioticoterapia, además disminuyó significativamente la dificultad respiratoria. Los exámenes de apoyo como hemograma y proteína $\mathrm{C}$ reactiva fueron normales, se solició una nueva RX tórax que mostró disminución del compromiso condensante y atelectásico (figura 2), por lo cual se suspendió la administración de antibióticos.

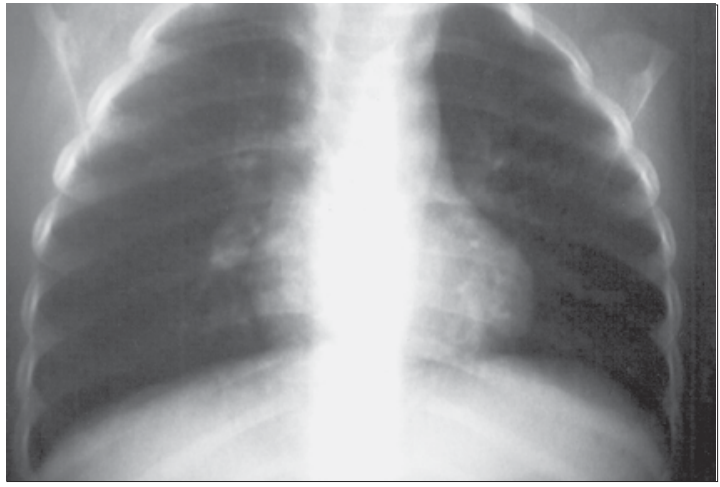

Figura 3.

La niña presentó una evolución satisfactoria, sin requerimientos de $\mathrm{O}_{2}$, el examen pulmonar se normalizó, por lo que la paciente fue dada de alta el sexto día de su hospitalización.

Evaluada en la Unidad de Broncopulmonar al mes de su alta, se encuentra asintomática. La RX tórax de control muestra escasos infiltrados intersticiales residuales (figura 3 ).

\section{Discusión}

Los hidrocarburos (HC) son componentes orgánicos que contienen carbono e hidrógeno usados en diferentes actividades de la vida diaria y laboral.

Los HC más frecuentemente involucrados en intoxicaciones son los alifáticos como parafina (kerosene), bencina, bencina blanca (encendedores), diluyentes de pinturas, petróleo; los aromáticos como benceno, xileno, tolueno y los terpenos como los derivados del aceite de pino.

La ingestión de estos productos es una causa frecuente de intoxicación, en pediatría corresponde al 5\%, los niños pueden ingerirlos accidentalmente especialmente si están contenidos en envases atractivos como en botellas de gaseosas. Los preescolares son los más frecuentemente afectados. Las intoxicación por productos industriales es de $13 \%$ aproximadamente, de este grupo el 55\% corresponde a HC (32\% alifáticos y $13 \%$ aromáticos).

El aparato respiratorio es el más comprometido en la intoxicación por $\mathrm{HC}$, pudiendo 
afectarse el sistema nervioso central, gastrointestinal, corazón, piel, hígado, riñón, entre otros.

Según las características físicas de los $\mathrm{HC}$ serán las manifestaciones clínicas observadas, es así como los $\mathrm{HC}$ tóxicos, es decir los que presentan mayor compromiso sistémico son de baja volatilidad y alta viscosidad (aromáticos), en cambio los no tóxicos presentan alta volatilidad y baja viscosidad (alifáticos y terpenos). Estos últimos producen mínimo daño tóxico sistémico pero potencialmente gran capacidad de daño por irritación química directa al aparato respiratorio y en consecuencia síntomas a nivel pulmonar ocasionados por la aspiración del HC líquido a la mucosa traquebronquial y/o inhalación de sus gases hacia las vía aérea distal, estas sustancias producen alteración del surfactante, lo que determina un aumento de la tensión superficial, conduciendo al colapso de la vía aérea, observándose zonas de atelectasia y otras de hiperinsuflación, la destrucción de los septos, alvéolos, capilares y del intersticio pulmonar, además del broncoespasmo alteran la relación v/q. La mortalidad se debe a insuficiencia respiratoria, con hipoxemia sin retención de $\mathrm{CO}_{2}$.

Los síntomas respiratorios están presentes en el $25-40 \%$ de los casos, siendo este hecho muy importante ya que la mortalidad se debe al compromiso pulmonar más que a alteraciones de otros órganos, estos síntomas progresan el primer día, luego se estabilizan y disminuyen en los próximos 5 días. Inmediatamente luego de la ingestión y/o aspiración se puede presentar tos seca, disnea y sofocación, menos frecuente cianosis, la sintomatología respiratoria puede aparecer precozmente o bien luego de horas, pero excepcionalmente más de seis, los más frecuentemente encontrados son cianosis, polipnea, aleteo nasal, retracción de partes blandas, la auscultación puede ser normal o encontrarse crépitos, roncus, sibilancias, los signos de condensación están presentes en 40-50\% de los casos. Los pacientes más severamente afectados pueden presentar obstrucción bronquial, taquipnea, hipoxia, hemoptisis, edema pulmonar y síndrome de distress respiratorio del adulto.

La radiología puede ser normal con signos clínicos y a la inversa pueden existir alteraciones radiológicas aún en ausencia de síntomas.
Aproximadamente un $75 \%$ tiene evidencia de compromiso radiológico el que habitualmente se manifiesta en forma precoz o dentro de las primeras seis horas, se caracterizan por aumento de la densidad parahiliar, infiltrados que pueden confluir presentándose como condensación y atelectasias basales, menos frecuentemente neumatocele, neumotórax y derrame pleural. En el $75 \%$ de los pacientes el compromiso es a derecha y en el $50 \%$ es bilateral. La máxima expresión se produce a las 72 horas y desaparece en semanas, en cambio la recuperación clínica ocurre entre tres a ocho días.

$\mathrm{Al}$ comienzo la fiebre y la leucocitosis son por efecto de la misma sustancia, sólo un pequeño porcentaje presenta una neumonía bacteriana que generalmente evoluciona satisfactoriamente, se puede producir desde las 2496 horas de la ingestión, se sospecha por persistencia de la fiebre por más de 24 horas, leucocitosis y progresión de la condensación en la RX tórax. Otras complicaciones como el derrame pleural y el neumotórax son poco frecuentes, pero de presentación precoz en los casos de intoxicación severa, la que corresponde al 3-5\%, la mortalidad es de $1-2 \%$, siendo la principal causa la insuficiencia respiratoria refractaria.

Deben hospitalizarse los pacientes si presentan síntomas en las primeras seis horas, aunque la RX tórax sea normal, si existe hipoxemia o si la ingesta fue de un producto muy tóxico. Los niños que no presentan síntomas después de seis horas y la RX tórax es normal se observan en su domicilio, pero ante la aparición de cualquier síntoma respiratorio deben volver a consultar.

El manejo como todo paciente intoxicado deben aplicarse las medidas básicas del ABC de la reanimación, evaluación clínica y de laboratorio.

Se debe practicar un buen aseo de la piel, están contraindicados la inducción de vómito y el lavado gástrico, por el peligro de aspiración. Uno de los pilares más importantes en el manejo es el apoyo respiratorio mediante la oxígenoterapia con mascarilla simple, con reservorio, presión positiva continua, ventilación mecánica convencional, vafo o ecmo, según corresponda. 
Los broncodilatadores se indican en el manejo de la obstrucción bronquial, en cambio los corticoides no han demostrado ser útiles. Los antibióticos profilácticos no se indican y sólo deben usarse cuando exista una neumonía bacteriana demostrada.

Finalmente, se debe educar a los padres en cuanto a dejar fuera del alcance de los niños cualquier producto tóxico o veneno y en espacial nunca almacenar estos productos en envases atractivos para los menores.

\section{Referencias}

1.- Truemper E, Reyes de la Rocha S, Atkinson D: Clinical characteristics, pathophysiology and management of hydrocarbon ingestion; case report and review of the literatura. Pediatr Emerg Care 1987; 3: 187-93.

2.- Orenstein DM: Neumonías de aspiración y por reflujo gastroesofágico. Procesos respiratorios relacionados. En: Nelson W, Behrman R, Kliegman R, Harbin A Nelson tratado de pediatría. $15^{\mathrm{a}}$ ed. USA: Mc GrawHill Interamericana SA, 1997.

3.- París E: Intoxicaciones en la infancia. En: Cerda M, París E. Cuidados intensivos en pediatría. Santiago de Chile: Ed. Mediterráneo, 1996.

4.- Karson KH Jr: Hydrocarbon poisoning in children. South med j 1992, 75: 839-41.

5.- Shih R: Hydrocarbons. En: Goldfrank L. Toxicologic emergencies. Stanford: Appleton \& Schuster Company, 1998.

6.- Litovitz T, White N, Watson W: Epidemiology of pediatric poison exposures: an analysis of 2003 poison control center data. Clin Ped Emerg Med 2005; 6: 68-75.

7.- Segev D, Szold O, Fireman E, Kluger Y, Sorkine P: Kerosene-induced severe acute respiratory failure in near drowning: reports on four cases and review of the literature. Crit Care Med 1999; 27: 1437-40.

8.- Ling LJ, Clark RF, Erickson TB: Secretos de la toxicología. Mc Graw-Hill Editorial Interamericana, 2002.

9.- Aglony M, Montecino L, Codoceo A, Sánchez I: Neumonía por hidrocarburos. En: Pediatría al Día, Santiago: Editorial Mediterráneo, 2000; 16 (4): 289-92.

10.- González E: Neumonía por hidrocarburos. En: Fielbaum $\mathrm{O}$, Herrera O. Enfermedades respiratorias infantiles $2^{\mathrm{a}}$ Ed, Santiago: Editorial Mediterráneo, 2002; 279-81.

11.- Llanos J, García C: Caso radiológico pediátrico. Rev Chil Enf Respir 2007; 23: 53-5.

12.- Bray A, Pirroni T, Marano P: Pneumatoceles following hydrocarbon aspiration. Eur Rdiol 1998; 8: 262-3.

13.- Kim KI, Kim CW, Lee MK, et al: Imaging of ocupational disease. Radiographics 2001; 21: 1371-91.

14.- Shannon $M$ : Ingestion of toxic substances by children. N Engl J Med 2000; 342: 186-91.

15.- Smith P: Neumonitis por aspiración. En: cuidados intensivos en pediatría $3^{\mathrm{a}}$ ed, Editorial Mosby/Doyma Libros, 1993.

16.- Bysani GK, Rucoba RJ, Noah ZL: Treatment of hydrocarbon pneumonitis. High frequency jet ventilation as a alternative to extracorporeal membrane oxigenation. Chest 1994; 106: 300-03. 